\title{
Kanserde Psikososyal Sorunlar Ve Psikososyal Onkolojinin Önemi
}

\author{
PSYCHOSOCIAL PROBLEMS IN CANCER AND THE IMPORTANCE OF PSYCHOSOCIAL \\ ONCOLOGY
}

\section{Eda ÜLGER ${ }^{1}$, Ahmet ALACACIOĞLU ${ }^{1}$, Abdullah Şeref GÜLSEREN², Gülbanu ZENCİR ${ }^{3}$, Lütfiye DEMİR $^{1}$, Mustafa Oktay TARHAN ${ }^{1}$}

${ }^{1}$ Katip Çelebi Üniversitesi Atatürk Eğitim Ve Araştırma Hastanesi Tıbbi Onkoloji Kliniği

${ }^{2}$ Katip Çelebi Üniversitesi Atatürk Eğitim Ve Araştırma Hastanesi Psikiyatri Kliniği

3Pamukkale Üniversitesi, Hemşirelik Yüksekokulu

\section{ÖZ}

Kanser, insan yaşamını ciddi anlamda etkileyen ve yaşam kalitesini azaltan çok boyutlu ve karmaşık bir hastalıktır. Kanser hastalarının tıbbi tedaviden en iyi yarar elde etmelerinde ve hastalık sürecinde yaşanan fiziksel, psikososyal ve ekonomik sorunların azaltılmasında psikososyal destek önemli bir rol oynar. Bu makalede kanser hastalarında görülen psikososyal sorunların neler olduğu, psikososyal onkoloji, önemi ve hangi yöntemleri kullandığı ele alınmaktadır.

Anahtar sözcükler: Kanser, psikososyal tepkiler, psikososyal onkoloji

\section{ABSTRACT}

\section{Eda ÜLGER}

Katip Çelebi Üniversitesi

Atatürk Eğitim Ve

Araştırma Hastanesi

Tibbi Onkoloji Kliniği

İZMIR

\begin{abstract}
Cancer is a multi-dimensional and complex disease that affect human life seriously and decrease the quality of life. For cancer patients, in getting the best benefit from medical treatment and reducing the physical, psychosocial and economic problems that lived during the disease, psychosocial support plays an important role. In this review, the psychosocial problems that lived by cancer patients, psychosocial oncology, it's importance and the methods which are used in psychososcial oncology are focused.

Keywords: Cancer, psychosocial reactions, psychosocial oncology
\end{abstract}

Kanser, günümüzde insan sağlığını tehdit eden en önemli hastalıklardan birisidir (1). Yüzyılın başlarında kanser, ölüme neden olan hastalıklar arasında daha gerilerde yer alırken, günümüzde dünyanın birçok ülkesinde ve Türkiye'de insan sağlığını tehdit eden en önemli hastalıklardan birisi olup kalp hastalıklarından sonra ikinci sırada yer almaktadır (1,2). Türkiye'de her yıl 300 bin kişiye kanser tanısı konulmaktadır. Dünya Sağlık Örgütü'nün verilerine göre 2008 yılında dünya nüfusu 6,7 milyar olup, 12 milyon yeni kanser olgusu ile birlikte kanserden kaynaklanan 7 milyon ölümün ve kanserli 25 milyon kişinin halen hayatta ya da tedavi gördüğü bildirilmiştir. 2020 yılında dünyada yıllık yeni kanser olgusu sayısının 2000 yılına göre \%65’lik bir artışla 17 milyona çıkacağı öngörülmektedir. 2030 yılında ise dünya nüfusunun 8,7 milyara ulaşacağı, yıllık 27 milyon yeni kanser olgusu, kanserden kaynaklanan yıllık 17 milyon ölüm ile birlikte son 5 yıl içinde yeni kanser tanısı konmuş 75 mil- 
yonluk rakamlara yükseleceği öngörülmektedir (3).

Her geçen gün görülme sıklığı artan kanser, bedensel zorlukların yanı sıra hastaların sosyal yaşamında ve hastalar üzerinde psikolojik etkisi ağır ruhsal sorunlara yol açabilmekte, bu durum da hastalığın seyrini ve tedaviye yanıtı olumsuz etkilemektedir. Kanserin tedavi süreci ağır ve uzun bir dönemi içerdiği için, hastaların psiko-sosyal destek almaları ruh sağlıklarının korunmasında ve hastalıkla baş edebilme becerilerinin geliştirilmesinde önem taşımaktadır.

Kanserli hastalar, yüksek oranda psikiyatrik komorbiditeye sahiptirler; yaklaşık olarak hastaların yarısı duygusal güçlükler yaşamaktadırlar. Psikososyal komplikasyonlar genellikle uyum bozuklukları, depresyon, anksiyete, azalan yaşam memnuniyeti ya da özgüven kaybıdır. Bu psikiyatrik koşullara bağlı olarak, nonspesifik distres ve anksiyete kanser hastalarında yaygın olarak görülür. Distres, psikolojik, sosyal ve manevi faktörlerin çoklu toplamıdır. Eğer bu faktörler şiddetliyse, distres, hastanın hastalıkla, semptomlarıla ve tedavinin komplikasyonlarıyla etkin bir şekilde başa çıkma kabiliyetini etkiler (4). Kanser ciddi ve kronik bir hastalık olmanın ötesinde; korku, umutsuzluk, suçluluk, çaresizlik, terk edilme ve ölüm duygusu tepki ve düşüncelerini çağrıştıran bir hastalık olarak algılanır. Bu nedenle kanser bir yıkım gibi algılanır ve dramatik anlamıyla kişinin ruhsal dengesinde bozulmaya neden olur. Bu nedenle kanser, tıbbi- fiziksel bir hastalık olmasının yanında, ruhsal ve psikososyal açıdan birçok sorunu da kapsayan bir olgudur (5). Gyllensköld'e göre kanser, doğrudan doğruya ölümle ilişkili olduğu, sinsice hareket ettiği, nedenleri, pek açıklanamayan zamanla kontrolün güçleştiği, kontrolden çıktığ1 ve büyük acılara neden olduğu, bireyi sosyal yönden etiketlediği ve soyutladığı için diğer kronik hastalıklardan daha korkunç ve tehdit edici olarak algılanır (6).

Kanserle baş eden bir hasta için iyileşmeye giden yolda, ne kadar etkili olursa olsun, yalnızca tıbbi tedavi protokolleri (kemoterapi, radyoterapi, cerrahi müdahale gibi) yeterli değildir. Tedavi sürecinde ve sonrasında hastanın psikososyal esenliğini kazanması ve bunu sürdürebilmesi de temel tedavi ölçütleri arasındadır (7). Günümüzde kanser, tanı ve tedavisi multidisipliner olarak ele alınması gereken çok yönlü sorunları olan bir hastalıktır. Kanser, bedensel bir hastalık olmasının yanı sıra ruhsal ve psikososyal açıdan birçok sorunu da beraberinde taşıyan kronik bir olgudur. Kanser hastaları tanı, tedavi, nüks ve palyatif bakım dönemlerde çeşitli duygusal, ruhsal, davranışsal reaksiyonlar geliştirirler. Bu nedenle kanser hastalarının bütüncül tedavi ve bakımlarında, tıbbi, psikiyatrik ve psikososyal boyutları da içeren tedavi planlanmalıdır (6). Kanser hastalarının yaşadıkları travmayı atlatmaları için ruhsal durumlarını ve motivasyonlarını olduğundan çok daha güçlü tutmak zorunda kaldıkları bu süreçte, psikososyal desteği tedavinin önemli bir parçası olarak görmek gerekmektedir. Bu noktada, kanser hastalarındaki sosyal, psikolojik, emosyonel, spritüel, yaşam kalitesi ve fonksiyonel görünüşü anlama ve tedavisiyle ilgilenen psikososyal onkoloji bilim dalına ihtiyaç duyulmaktadır. Psikososyal onkoloji kanserden etkilenen bireylerin yaşam kalitesini artırabilecek insani ihtiyaçlarını ele alan bütüncül bir yaklaşımıdır.

Bu makalede psikososyal açıdan kanser ve psikososyal onkolojinin önemi ele alınacaktır. Konunun daha iyi anlaş1labilmesi için kanserde görülen psikososyal tepkiler, kansere ek olarak görülen psikiyatrik bozukluklar, psikososyal onkolojinin önemi ve tedaviye etkisine değinilecektir.

\section{KANSERLİ HASTALARDAKİ SOSYAL SORUNLAR VE SOSYAL DESTEK}

Kanser hastalığı kuşkusuz, tanıyı alan bireylerin ve yakınlarının, bilişsel, psikolojik, duygusal, tinsel ve sosyal alanlarında derin etkiler yapmaktadır. Gerek hastalığın tanısında gerekse tedavi sürecinde hastanın benlik sayg1sında, bedeniyle ilgili algısında, yaşam kalitesinde, hayatının işleyişinde, seksüel durumunda, kişisel ve sosyal rollerinde, aile ve çevresiyle olan ilişkilerinde değişiklik yaratmakta, sosyal desteğe duyulan ihtiyacı artırmaktadır (7). Sosyal destek, yaşamda ortaya çıkan olumsuz olayların fiziksel sağlık ve kendini iyi hissetme üzerindeki zarar verici etkisini azaltmaya ve bu olumsuzluklar karşısında strese karşı tampon işlevi görmeye yardımcı olmaktadır (8). Sosyal destek, bireyin duygusal sorunlarıyla mücadele edebilmesi için psikolojik dinamiklerini güçlendiren, bireye duygusal, maddi ve bilişsel yardım sağlayan aile, 
arkadaşlar, komşular ve kurumlardan aldığı destek olarak tanımlanabilir. Sosyal desteğin, fiziksel ve ruhsal çok sayıda hastalığın ortaya çıkışı, gidişi ve süresi üzerinde önemli etkilerinin olduğu bilinmektedir. Genel olarak güç bir durum içindeki bireye sağlanan fiziksel ve psikolojik bir yardım görüntüsüyle sosyal destek; bireylerin sevgi, bağlılık, benlik saygısı ve bir gruba ait olma gibi temel sosyal gereksinimleri karşılar (9). Sosyal destek, kanser hastalarının yaşadığı psikolojik gerilimlerle başa çıkmada yardımcı olabilecek en önemli kaynaklardan biridir.

\section{KANSERDE KARŞILAŞILABİLEN SOSYAL SORUNLAR;}

-Bazı aile bireyleri birbirine daha çok yakınlaşmakta, bazıları ise birbirinden uzaklaşmaktadır,

-Eşler, genellikle evle ilgili rol ve sorumlulukların değişmesi ve hasta eşin duygusal sorunları karşısında yetersizlik ve çaresizlik hissetmektedirler,

-Aile bireyleri ve arkadaşlar kendi alışkanlıkları ve hastaya karşı nasıl davranacakları hakkındaki belirsizlik yüzünden hasta ile yakın olmaktan kaçınabilirler, bu da sosyal izolasyona neden olmaktadır,

-Hasta, ailede ve toplumdaki rol ve sorumluluklarını yerine getiremeyebilir,

-Mesleki yaşamda performans eksilmesi, işe gidememe, buna bağlı sosyal konumunda ve maddi kazançta kayba uğrayabilirler,

-Kanser hastası olmaktan kaynaklanan etiketlenme sorunu yaşayabilirler,

-Yakınlarla ve tedavi ekibiyle sağlıklı iletişim becerilerini geliştirememekten kaynaklanan sorunlar yaşayabilirler,

-Yaşam planı ve önceliklerini yeniden oluşturmaya gereksinim duyabilirler ki bu durum da hastanın psikolojisi üzerinde yoğun bir baskıya neden olabilir,

-Hastalarda beden imajında ve benlik saygısında değişim, yorgunluk, aktivite intoleransı, immobilite ve immünosüpresyone sekonder olarak enfeksiyona yatkınlık gibi nedenlere bağlı sosyal izolasyon mey- dana gelebilmekte; sosyal izolasyon da anksiyete ve depresyonu artırabilmektedir (10).

\section{KANSERDE PSİKOLOJİK SORUNLAR}

Günlük yaşantının içerisinde "kanser" kelimesi bile başlı başına olumsuzlukları çağrıştırır. Kanser tanısı olasılığı olan ya da tanısı alan hastalarda ise olumsuz duygu ve düşüncelerin gelişmesi neredeyse kaçınılmazdır. Kanser bir yıkım gibi algılanır ve en dramatik anlamıyla kişinin psikolojik dengesinde krize neden olur. Kriz; sağlıklı yaşamdan, hastalık ve ölüm tehdidine uyuma uzanan bir süreçtir. İnsanlar, kanser tanısı karşısında birçok farklı tepkiler gösterirler. Kanser hastaları tanı, tedavi, nüks ve terminal dönemlerde çeşitli ve değişik duygusal, ruhsal, davranışsal tepkiler gösterirler. Tanıyı takiben şok hali, inanamama, inkar, kızgınlık, depresif duygu durum, uyku, iştah ve günlük faaliyetlerde bozulma gelişir (11). Aslında şok, tepki, direnme ve uyum süreçleri tüm dönemlerde yeniden yaşanmaktadır (12). Kanser tanısına normal yanıt, endişe, gerginlik, kaybedilen sağlık için keder ve üzüntüden hastalığın önemini yadsıma, bu süreci bir savaş gibi algılama ya da kaderci bir kabullenmeye kadar değişir. Bolund kanser tanısının konulması ile şok, tepki, direnme ve uyum olmak üzere toplam dört aşamalı bir sürecin yaşandığını bildirmiştir $(12,13)$. Elisabeth Kübler Ross da kanserde ortaya çıkan psikososyal aşamaları inkar, öfke, pazarlık, depresyon ve kabullenme olmak üzere beş aşamada tanımlamıştır (11).

Genel olarak kanser tanısına ilk aşamada gösterilen en yaygın tepki şok olma ve inanmamadır. Kişi, kendi bedenine yabancılaşır ve kendi bedenine güvenmez. Kısa bir süreliğine kişinin iç dünyası karışıktır. Bu durum birkaç saatten birkaç gün ya da haftaya kadar uzayabilir. Bu aşamada en yaygın uyum biçimi, inkardır. İnkar katlanılması güç olan gerçeği bilinç dışında tutma, benlik bütünlüğünü koruma çabasıdır $(12,13)$.

İkinci aşama, hastanın gerçeği yavaş yavaş kabullenme sürecine girdiği dönemdir. Bu aşamada, temel tepki biçimi kaygıdır. Kaygıyı yok etmek için hasta inkar, bastırma, karşıt duruş gibi tepkileri de bu aşamada görülen reaksiyonlardandir $(12,13)$.

Tedavinin en aktif olduğu dönem sona erince üçüncü 
aşamaya geçilir ve hasta yeni durumuna uyum sağlamaya çalışır. Yaşamında artık eskiye döndüremeyeceği değişiklikler olmuştur. Ölüme bu kadar yaklaştıktan sonra yaşama bakış açısını sorgulayabilir. Bu noktada, bundan sonra yaşamı nasıl değerlendirmek gerektiği sorusu, bu hastaların en önemli sorularından biridir $(12,13)$.
Son aşama ise hastanın gerçeği kabul edip, enerjisini ve ruhsal gücünü yeni yaşamına yönelttiği uyum dönemdir. Kişi yeni kimliğini ve hastalığını benimsemeye başlar. $\mathrm{Bu}$ dönemle birlikte, kişi yaşamını, geçmişini, geleceğini, varoluşunu yeniden yorumlaya başlar. Güven ve denge arayışı içindedir (Tablo, 11-14).

Tablo. Kanserde psikolojik tepkiler

\begin{tabular}{|c|c|c|}
\hline & Uyuma Yönelik Tepkiler & Uyuma Yönelik Olmayan Tepkiler \\
\hline $\begin{array}{c}\text { Tanı } \\
\text { Öncesi }\end{array}$ & 1. Kanser olasılığı ile ilgili kaygı geliştirme & $\begin{array}{l}\text { 1. Kanser tanısı konmadan hastalık } \\
\text { belirtileri geliştirme } \\
\text { 2. Hastalık olasılığının inkar edilmesi } \\
\text { ve tedavide gecikme }\end{array}$ \\
\hline $\begin{array}{c}\text { Tanı } \\
\text { Aşaması }\end{array}$ & $\begin{array}{l}\text { 1. Şok olma } \\
\text { 2. İnanamama } \\
\text { 3. Başlangıçta kısmi inkar } \\
\text { 4. Kaygı } \\
\text { 5. Kızgınlık, isyan, suçlayıcı duygular } \\
\text { 6. Depresif mizaçlı uyum }\end{array}$ & $\begin{array}{l}\text { 1. Kesin inkar, tedaviyi reddetme } \\
\text { 2. Ölümün kaçınılmaz olacağı } \\
\text { düşüncesi ile tedaviyi reddetme }\end{array}$ \\
\hline Tedavi Aşaması & $\begin{array}{l}\text { Cerrahi Tedavi } \\
\text { 1. Cerrahi girişimin geciktirilmesi } \\
\text { Radyoterapi } \\
\text { 1. Işın tedavisinin etkilerinden korkma } \\
\text { 2. Terk edilme korkusu } \\
\text { Kemoterapi } \\
\text { 1. Yan etkilerinden korkma } \\
\text { 2. Vücut imajı değişiklikleri } \\
\text { 3. Kaygı, izolasyon eğilimi, hafif depresif duygu } \\
\text { durumu } \\
\text { 4.Alturuistik duygular (organlarını bağışlama) }\end{array}$ & $\begin{array}{l}\text { 1. Ameliyat sonrası reaktif depresyon } \\
\text { 2. Vücut imajı değişiklikleri ve uzamış } \\
\text { ciddi elem reaksiyonu }\end{array}$ \\
\hline Tedavi Sonrası & $\begin{array}{l}\text { 1. Normal baş etme düzeneklerine ve } \\
\text { hastalık-tedavi sınırları içinde yaşama dönüş } \\
\text { 2. Nüks korkusu }\end{array}$ & $\begin{array}{l}\text { 1. Şok olma } \\
\text { 2. İnanamama } \\
\text { 3. Kısmi inkar } \\
\text { 4. Kayg1 } \\
\text { 5. Kızgınlık } \\
\text { 6. Depresif duygu durum }\end{array}$ \\
\hline & 1. Yeni bilgi araştırma ve çeşitli tedavi & 1. (Major) Depresyon \\
\hline $\begin{array}{l}\text { Hastalığın Seyri ve } \\
\text { İlerlemesi }\end{array}$ & Olasılıklarına dönük arayış ve konsültasyonlar & \\
\hline $\begin{array}{l}\text { Terminal/ Palyatif } \\
\text { Dönem }\end{array}$ & $\begin{array}{l}\text { 1. Terk edilme korkusu, ağrı, bilinmezlik } \\
\text { korkusu, varoluşçu endişeler } \\
\text { 2. Ölüm düşüncesine bağlı kişisel elem duygusu ve kabul- } \\
\text { leniş }\end{array}$ & $\begin{array}{l}\text { 1. Depresyon } \\
\text { 2. (Akut) Deliryum }\end{array}$ \\
\hline
\end{tabular}




\section{KANSERDE PSİKIYYARİK BOZUKLULAR}

Kanser tanısı alan hastalarda görülen psikiyatrik sorunlar ve sıklıkları, kanserin türüne, hastalığın doğasına, kullanılan tedavi ve yan etkilerine bağlı olarak gelişmektedir. Kanser hastalarının hepsinde psikiyatrik bozukluk ortaya çıktığı düşüncesi de hastanın tüm tepkilerinin "normal" olarak kabul edilmesi gerektiği düşüncesi de yanlıştır (15).

Yapılan çalışmalarda, kanser hastalarının \%47'sinde tanı konacak düzeyde ruhsal bozukluk bildirilmiştir. Tıbbi hastalar genelinde bildirilen \%20-40 oranına göre bu oldukça yüksek bir orandır. En sık görülen ruhsal bozukluklar; depresyon, kaygı bozuklukları ve organik beyin sendromu'dur (16).

Kanserli hastalarda ortaya çıan psikiyatrik bozuklukları şu şekilde sınıflandırabiliriz:

- Uyum bozuklukları

- Depresif sendromlar

- Anksiyete bozuklukları

- Organik beyin sendromları (deliryum, demans ve diğer organik psikiyatrik sendromlar, kemoterapötik ajanların nöropsikiyatrik yan etkileri)

- Kişilik ve tutum değişiklikleri

- Ağrılı sendromlara eşlik eden psikiyatrik sendromlar

- İştahsızlık, bulantı-kusma (kemoterapiye bağlı) (16).

Araştırmalarda belirtilen psikiyatrik rahatsızlıkların görülme oranı ise \%13 şiddetli depresyon, \%68 depresif uyum bozukluğu, \%8 organik mental bozukluk, \%8 kişilik bozukluğu, \%4'ünün kaygı bozukluğu şeklindedir (17). Radyoterapi alan hastalarda depresyonun sıklığ $\%$ 81 gibi yüksek bir orana ulaşmaktadır. \%38'inde şiddetli depresyon, \%43'ünde depresif uyum bozukluğu görülmektedir (17).

Yaşam tarzı ve rol değişiklikleri, ekonomik güçlükler, hastaya yönelik bakımın artması ve geleceğe yönelik belirsizlik ve korku nedenleriyle hastada oluşan anksiyete, depresyona neden olabilmektedir (18). Ayrica bedensel sağlığın yitimine duyulan üzüntü ve ölüme ilişkin kaygı gibi nedenlerle klinik düzeyde depresyon görülebileceği bildirilmiştir $(19,20)$ Kanserli hastalarda sıkça görülen depresyon varlığı tedaviye uyumu bozarak hastanede kalış süresini ve tedavi masraflarını artırmakta, hastalığın seyrini olumsuz yönde etkileyebilmektedir. Ateşçi ve ark çalışmalarında kanser hastalarında psikiyatrik bozukluk oranını \%28,7 olarak bildirmiştir (21). Depresif duygudurum ile giden uyum bozukluğu ve majör depresyon tan1ları en sık saptanan iki tanı grubunu oluşturmakla birlikte, özellikle terminal dönem kanser hastalarında organik mental bozukluğun görülme sıklığının yüksek olduğu bildirilmiştir (21). Minagawa ve ark bu oranı \%53, deliryum-demans tanılarını \%42 olarak saptamışlardır (22). Turan, kanser tanısı alan hastaların \%30-40'ında psikiyatrik ve psikososyal morbidite ortaya çıktığını, hastaların $\% 23$ 'ünde depresyon, \%20'sinde anksiyete ve \%26'sında uyum güçlüğü saptandığını belirtmektedir (18). Derogatis ve ark yaptıkları çalışmada uyum bozukluğunu \%68, majör depresyonu \%13, organik beyin sendromunu $\% 8$, kişilik bozukluğunu \%7 ve anksiyete bozukluğunu \%4 olarak bildirmiştir (23).

Deliriyum, kanserli hastalarda, özellikle terminal dönem hastalarında çok sık görülen, sıklıkla gözden kaçan bir durumdur. Bir çalışmada hastaların \%46,9'unda delirium geliştiği, ancak bunların sadece \%43'ünün tanısının konulabildiği gözlenmiştir. Delirium tedavi edilmediğinde kalıcı unutkanlık, dikkat azlığı, konsantrasyon güçlüğü gibi kognitif belirtilere neden olmaktadır (17).

Tüm bu veriler göz önüne alındığında, kanser hastalarında görülen psikolojik ve psikiyatrik sorunların göz ardı edilemeyecek düzeyde olduğu ve bu sorunların hastalığın seyrini ve hastanın yaşam kalitesini olumsuz etkilediği görülmektedir. Bundan yola çıkılarak, kanserin tedavisinin yapılması ve hastaların yaşam kalitelerinin artırılmasının yeterli olmadığı, psikososyal sorunlarının çözümlenerek hayat kalitelerinin yükseltilebilmesi için onkolojipsikiyatri ve sosyal hizmetlerin birlikteliği ile multidisipliner bir yaklaşımın gerekliliği ve önemi ortaya çıkmaktadır.

\section{PSÍKOSOSYAL ONKOLOJI}

Kanser tanı ve tedavilerinin yaygınlaşması, tıp alanındaki gelişmeler, iletişim araçları ile yapılan uyarı ve eğitim çalışmalarının yoğunluk kazanması, insanların sağlık kuruluşlarına başvurmalarını kolaylaştırmaktadır. $\mathrm{Bu}$ da 
hem kanser tanısı alan bireylerin sayısında bir artışa hem de kanserde erken tanı ve tedaviden olumlu sonuçlar alınmasını sağlamaktadır. Her ne kadar "kanser" sözcüğü halen "ölüm"le eş tutulsa da erken tanı ve tedavideki yenilikler sayesinde kanserli hastalar daha uzun süre yaşamaktadirlar (24).

$\mathrm{Bu}$ nedenle kanser hastalarının psikolojik kaygı ve acılarını azaltmak, ölümcül hastalıklarla yüzleşmesini kolaylaştırmak, tedaviye uyumunu sağlamak, yaşam kalitesini arttırmak, duyguların ifadesine yardımcı olmak, mücadele ve yaşama gücünü arttırmak, hastalığın yarattığı çok yönlü krizle sağlıklı baş etmeye yardımcı olmak için psikososyal desteğe ihtiyaç vardır. Hastanın mevcut psikososyal sorunlarının saptanıp uygun psikososyal desteğin yapılması için psikososyal onkolojiye gereksinim vardır.

Psikososyal onkoloji, tüm aşamalarda kanserin sosyal, psikolojik, duygusal, ruhsal ve işlevsel yönlerinin anlaşılması ve tedavisiyle ilgili bir uzmanlık alanıdır. Psikososyal onkoloji, kanserden etkilenen bireyler ve onların yakınları için yaşam kalitesini en iyi şekilde artırabilen ya da optimize edebilen, ihtiyaçları gideren, kanser tedavisine bütüncül bir yaklaşımı içerir (25).

Dünya Sağlık Örgütü 2008 yılında yayınladığı raporunda; onkolojik bakımın psikososyal bileşenlerinin ulusal kanser bakımı planının bir parçası olması, psiko-onkoloji hizmetlerinin kanser tedavisi servisinde sunulması gerektiğini bildirmektedir. Kanser hastaları ve yakınlarına tedavi sırasında ve sonrasında psikososyal onkoloji danışmanlığı hizmeti ile bir dizi psikososyal desteğin sağlanması; bu kişilerin durumları hakkında açık ve ücretsiz bilgilendirilmeleri, ihtiyaç ve tercihlerine saygı gösterilmesi, sağlık personeline geçerli psikososyal değerlendirme araçları, eğitimi, gözetim sağlanması ve bunlarla hastalar ve yakınlarının psikososyal ihtiyaçlarına yeterli yanıt verebilmelerine, iyi iletişim kurabilmelerine ve tıbbi karar alma sürecinde paylaşıma yardımcı olunması gerekliliğine vurgu yapılmaktadir (26).

Psikososyal onkolojinin ilgi alanları (14):

- Kanserin ve tedavi programlarinin hastalar, yakınları ve tedavi ekibi üzerindeki psikolojik etkilerini araştırmak ve psikolojik destek sunmak,
- Psikolojik ve davranışsal etmenlerin, kanser riski ve seyrindeki etkilerini araştırmak ve bu alanda tanı ve tedavi konusunda araştırmalar yapmak,

- Kanser olgusunun ya da tedavi yöntemlerine ilişkin ortaya çıkan psikolojik reaksiyonların çözümlenmesi, hasta-aile-tedavi ekibinde ortaya çıkabilecek iletişim sorunlarının çözümlenmesini sağlamak,

- Öyküsünde psikiyatrik yönden riskli olan bilgilerin önceden belirlenip izlenmesi, akut tedavi döneminin dişında izlenme ve kontrol döneminde, psikiyatrik bakımın sağlanması ve uzun dönemde ortaya çıkabilecek ruhsal sorunların çözülmesini sağlamak olarak s1ralanabilir.

Kanser hastaları tanı, tedavi ve palyatif dönemlerde çeşitli ve değişik duygusal, davranışsal reaksiyonlar geliştirirler. Kanser hastalarının psikososyal açıdan doğru değerlendirilmesi için birçok faktör göz önünde bulundurulmalıdır. Bu faktörler;

1. Hastalı̆̆ın özellikleri: Etkilenen organ, işlev kaybı olup olmadığı, tedavinin komplikasyonları,

2. Hastanın bir birey olarak özellikleri: Hastalığa ilişkin genel algı, kişilik yapısı, yaşı, yaşam dönemi, baş etme yöntemleri, geçmişte geçirdiği hastalıklara verdiği tepki, bir yakınında kanser bulunma öyküsü,

3. Psikososyal çevre: Ailenin, toplumun hastalığı alg1lama şekli, hastanın aile ile ilişkisi, hasta-aile ve tedavi ekibi ilişkisi ve işbirliğidir (27).

Kanserde psikolojik tedavi girişimleri, danışmanlık, eğitim veya psikoterapötik yollarla baş etme davranışını geliştirmek için uygulanan sistematik çabalardır. Kanserle birlikte ortaya çıkan olumsuz duygu ve tepkilerin serbestçe ifade edilmesini ve hastalıkla ilgili düşüncelerin anlatılmasını cesaretlendirmek, psikososyal uyumunu sağlayarak yaşam kalitesini artırmak, hasta, aile ve sosyal etkileşim alanları arasındaki ilişkiyi güçlendirmek bu çabalardandır (14). Bu bağlamda hastanın ailesine yönelik psikososyal tedavi de önemlidir. Aileye yönelik psikososyal tedavinin amaçları; hastalığın aile bireyleri üzerindeki etkisini araştırmak, durumu etkileyen, önceden varolan ya da hastalıkla birlikte ortaya çıkan psikopatolojik tepkileri 
tanımlamak, hastalıkla ve tedavi ile ilgili duyguları, düşünceleri paylaşmak, hasta ve aileyi bir araya getirerek hastalık hakkındaki duyguların paylaşılmasını cesaretlendirmektir (28).

Kanser hastalarına en uygun tıbbi hizmet, hastalığ davi ederken fiziksel tedavi ve bakımla birlikte psikiyatrik tedavi ve psikososyal bakım hizmetinin eş zamanlı ve eş güdümlü ekip olarak sunulmasıyla mümkündür (25).

Kanser tedavisi, onkolog, psikiyatrist, psikolog, sosyal hizmet uzmanı, hemşire, diyetisyeni içeren multidisipliner bir yaklaşımı gerektirmektedir. Onkolojide hizmet veren personel, birçok biyopsikososyal sorunla mücadele eden hastaya karşı sempatik, anlayışlı ve ulaşılabilir bir şekilde yaklaşmalıdır. Psikososyal destek veren sağlık personeli, hastanın sorunlarını açıkça ifade etmesini sağlamalı, hastalık ve tedavinin yol açabileceği sıkıntılara karşı hastayı bilgilendirmeli, hastanın psikososyal bakımdan ihtiyaçlarını belirleyip bu ihtiyaçların karşılanmasını sağlamalıdır. Onkolojide çalışan psikiyatristin görevi mevcut psikiyatrik sorunların saptanıp tedavi edilmesiyken, psikolog hastaya psikolojik destek vermektedir. Birimde çalışan sosyal hizmet uzmanının görevi ise kanser hastalarına duygusal destek sağlamak ve destek grupları gibi psiko-sosyal müdahalelerle hastaların uyumunu kolaylaştırmaktır (7). Eğitici hemşire, hastalık ve tedavinin neden olabileceği sorunlar hakkında hastaya bilgi vererek tedavi öncesi hastalarda yaşanan, belirsizlikten ve bilgisizlikten kaynaklı psikolojik sorunların azaltılmasında rol oynamaktadırlar. Yapılan bir araştırmada iyi bir bilgilendirmeyle hastaların psikolojik sorunlara daha az maruz kaldığı ve tedaviye daha iyi uyum sağlayabildikleri saptanmıştır (29).

Hastalık, bulunduğu organ, hastalığın türü, belirti ve bulguları, hastanın yaşı, kişilik yapısı, hastalıklara ilişkin deneyim ve düşünceleri, sosyokültürel düzeyi, baş etme süreçleri, çevresel destek sistemleri hastalığa uyumda rol oynamakta ve kişiden kişiye değişkenlik arz etmektedir. Tüm bu faktörler kanserli hastaya bakım veren sağlık profesyonelleri için göz önünde bulundurulması gereken unsurlardır (30).

\section{KAYNAKLAR}

1. VIII. Ulusal Meme Hastalıkları Kongresi Özet Kitapçığı:
363, İstanbul 2005; 21-24 Eylül.

2. Kızılcı S. Kemoterapi alan hastalar ve yakınlarının yaŞam kalitesinin etkileyen faktörler. Cumhuriyet Üniversitesi Hemşirelik Yüksekokulu Dergisi 1999; 3:18-26.

3. http://www.who.int/mediacentre/newa/releses/2003/pr27/ en/

4. Steven DP, Kenneth LK. Management of psychiatric and psychologic disorders in patients with cancer. Psycho-oncology 2012.

5. Altuğ B, Kaya N, Encirli Ş, Dura S, Kucur R. Kanser hastalarında psikiyatrik semptom dağılımı. IV. Anadolu Psikiyatri Günleri, Konya 1995; 268-272.

6. Anuk D, Özkan M, Alçalar N. İ. Ü. İ. İ. F. Konsültasyon - liyezon psikiyatrisi bilim dalı psikoonkoloji çalışmalarının 2 yıllık dökümü. Konsültasyon-Liyezon Psikiyatrisi Kongre Kitabı: Düz: Özkan S, İstanbul 1999; 174- 181.

7. Tuncay T. Kanserle baş etmede destek grupları. Toplum ve Sosyal Hizmet 2010; 21 . Sayı.

8. Şahin D. Sosyal Destek ve Sağlık. Ed: Okyayuz UH Sağlık Psikolojisi. (1. Baskı, 79-106). Türk Psikologlar Derneği Yayınları, Ankara 1999.

9. Aksüllü N. Huzurevinde ve evde yaşayan yaşlılarda algılanan sosyal destek etkenleri ile depresyon arasındaki ilişki. Anadolu Psikiyatri Dergisi 2004;5: 76-85.

10. Dedeli Ö, Karadeniz G. Kanser ağrısının kontrolü ile psikososyal- spiritüel modelin birleştirilmesi; Ağrı 2009;21:45-53.

11. Elbi H. Psiko- onkoloji. 3P Dergisi 1998; 6: 5- 7.

12. Anuk D. Kanser, kanserli hasta, hasta ailesi ve tedavi ekibi. Konsültasyon-Liyezon Psikiyatrisi Kongre Kitabı: Düz: Özkan S, İstanbul 1999;160-173.

13. Özkan S. Psikiyatrik Tip: Konsültasyon Liyezon Psikiyatrisi, İstanbul 1993.

14. Özkan S. Psikiyatrik ve psikososyal açıdan kanser. Konsültasyon-Liyezon Psikiyatrisi Kongre Kitabı, Düz: Özkan S, İstanbul 1999; 140-153.

15. Önen- Sertöz Ö. Kanserli hastada gözlenen ruhsal hastalıkların farmakolojik tedavisi, Ed: Uyar M, Uslu R, Kuzeyli- Yıldırım Y, Kanser ve Palyatif Bakım, 2006; 175-196

16. http://www.hastaokulu.org/index.php?t=2\&p=683\&l=279.

17. http://www.htanoropsikiyatri.com/kanser destek.html.

18. Turan AH. Kanser Hastalarında Anksiyete, Depresyon, 
Uyum Güçlüğü Prevelansı ve Bunların Psiko-sosyal Durumla İlişkisinin İncelenmesi. İstanbul Üniversitesi Onkoloji Enstitüsü Yüksek Lisans Tezi, İstanbul 1992.

19. Angelino AF, Treisman GJ. Majör depression and demoralization in cancer patients: diagnostic and treatment considerations. Support Care Cancer 2001; 9: 344-349.

20. Elbi H. Kanserli Hastada Depresyon, Depresyon, Ed: M. Bekaroğlu, Trabzon 1994; 217-223.

21. Ateşçi FÇ, Oğuzhanoğlu NK, Baltalarlı B Karadağ F, Özdel O, Karagöz N. Kanser hastalarmda psikiyatrik bozukluklar ve ilişkili etmenler. Türk Psikiyatri Dergisi 2003;14: 145-152.

22. Minagawa H, Uchitomi Y, Yamawaki S, et al. Psychiatric morbidity in terminally ill cancer patients. Cancer 1996; 78: 1131-37.

23. Tavil A. Kanserli Hastalarda Psikiyatrik Morbidite.
İstanbul Üniversitesi Cerrahpaşa Tıp Fakültesi Psikiyatri Anabilim Dalı Uzmanlık Tezi, İstanbul 1996.

24. Yıldırım S, Gürkan A. Psikososyal Açıdan Kanser ve Psikiyatri Hemşiresinin Rolü. Ege Üniversitesi Hemşirelik Yüksek Okulu Dergisi 2010; 26: 87-97.

25. http://www.capo.ca/patient-family-resources/what-ispsychosocial-oncology.

26. Boyle P, Levin B. Dünya Kanser Raporu 2008. Lyon, Uluslararası Kanser Araştırmaları Kurumu.

27. http://www.mainboard24.com/saglik-genel/361069-kanserli-hastalara-psiko-onkolojik-destek.html

28. http://www.saglikinfo.com/index.php? $\mathrm{l}=279 \& \mathrm{p}=683 \& \mathrm{t}=2$.

29. Montgomery C, Lydon A, Llyoyd K. Psychological distress among cancer patients and informed consent. Journal of Psychosomatic Research 1999; 46: 241-245.

30. www. acibademhemsirelik.com/e-dergi 